ORIGINAL ARTICLE

AFRICAN JOURNAL OF CLINICAL AND EXPERIMENTAL MICROBIOLOGY. JANUARY 2014 ISBN 1595-689X VOL15 No.1 AJCEM/1322

COPYRIGHT 2014 http://dx.doi.org/10.4314/ajcem.v15i1.1

AFR. J. CLN. EXPER. MICROBIOL 15(1): 1-8

\title{
DIVERSE GENETIC SUBTYPES OF HIV-1 AMONG FEMALE SEX WORKERS IN IBADAN, NIGERIA
}

${ }^{* 1}$ Fayemiwo, S. A., ${ }^{2}$ Odaibo, G. N. ${ }^{3}$ Sankale , J.L., ${ }^{1}$ Oni, A.A., ${ }^{1 B a k a r e, ~ R . ~ A ., ~}{ }^{2}$ Olaleye, O. D. and ${ }^{4}$ Kanki, P.

Departments of ${ }^{1}$ Medical Microbiology and ${ }^{2}$ Virology, College of Medicine, University College Hospital, Ibadan, Nigeria and

${ }^{3}$ A.P.I.N., Harvard School of Public Health, Boston, MA , USA.

Running title: Genetic subtypes of HIV-1 among female sex workers in Nigeria.

Keywords: Diverse, HIV, subtypes, Female Sex workers and Vaccine

${ }^{*}$ Correspondence: Fayemiwo, S. A., Department of Medical Microbiology and Parasitology, College of Medicine, University of Ibadan, Ibadan. Nigeria. E-mail address: dayteet@yahoo.com

\begin{abstract}
Background:

Genetic diversity is the hallmark of HIV-1 infection. It differs among geographical regions throughout the world. This study was undertaken to identify the predominant HIV-1 subtypes among infected female sex workers (FSWs) in Nigeria. Methods: Two hundred and fifty FSWs from brothels in Ibadan Nigeria were screened for HIV antibody using ELISA. All reactive samples were further tested by the Western Blot Techniques. Peripheral Blood Mononuclear Cells (PBMCs) were separated from the blood samples of each subject. Fragments of HIV Proviral DNA was amplified and genetic subtypes of HIV-1 was determined by direct sequencing of the env and gag genes of the viral genome followed by phylogenetic analysis. Results: The age of the FSWs ranged from 15 to 55 years old (Mean $=25.8$ years, SD $=3.74)$. Majority were Nigerians while others $(1.6 \%)$ were from neighboring West Africa countries. Four ( 1.6\%) of the FSWs were active for less than one year as sex workers, and the mean length of sex work was 2.80 years ( Range $=1.0-15.0$ years ). Sixty-four $(25.6 \%)$ of the 250 CSWs were positive for HIV-1 while $7(2-8 \%)$ had dual infections to HIV-1 / HIV-2. Among the 34 HIV-1 strains characterized by sequencing, 19 (55-9\%) were subtype G, 9 (26.5\%) CRF02_A/G, 3 (8.8\%) CRF06_cpx while $1(2.9 \%)$ each were identified as subtype C, CRF01_A/E and CRF09_cpx respectively. Nineteen (55.9\%) of the FSWs with subtype G had been active in the sex work for between one to five years. The youngest of the HIV -1 infected FSWs with sexual activity of less than a year had subtype G strain. There is a significant probability that infection with this subtype occurred with a short incubation period $(p<0.05)$. Conclusion: This study showed a wide range of HIV- 1 subtypes among FSWs in Nigeria. The situation poses serious challenge for the design of HIV vaccine candidate for use in Nigeria.
\end{abstract}

\section{INTRODUCTION}

The Acquired Immune Deficiency Syndrome (AIDS) epidemic has exacted a terrible toll in terms of loss of life and decreased quantity of life worldwide, especially in Africa, where $70 \%$ of deaths from HIV-1 infection have occurred (1).

The first case of AIDS in Nigeria was reported in 1986. From 2 cases in 1986, it has been estimated that 4,050,000 HIV infections have occurred in Nigeria², and it has spread extensively to the rural areas of the Country $(3,4,5)$.

In Africa, infection has been mainly by heterosexual intercourse, with Female sex workers (FSWs), long distant truck drivers and migrant labour serving as vehicles of spread (5).
Female sex workers (FSWs) have been at high-risk of infection since the beginning of the HIV epidemic all over the world. Multiple sex partners, irregular condom use, and co-infection with other sexual transmitted infections (STIs) are the principal risk factors for HIV infection among FSWs (7). Between 1995 and 2003 the prevalence rose from $6.4 \%$ in STD patients (8) to $34.3 \%$ in FSWs (9). The penetration into the general population cannot be over emphasized.

In women, the glandular epithelia have HIV in the zone of transformation between the columnar and squamous cell of the cervix (10). While in men, HIV is detectable in seminal cells, some sperm cells and their precursors (11). Because of high incidence of sexually transmitted infections (STIs) in African sex workers, immunologic stimulations to this infection may be higher than among the general African population (12). 
HIV-1 and HIV-2 show heterogeneity among isolates (13). On the basis of the phylogenetic analysis of the env and gag genes, HIV-1 has been divided into three distinct groups $(\mathrm{M}, \mathrm{O}, \& \mathrm{~N}$.), all of which cause AIDS in infected individuals. Group M ("For Major") comprises the greatest majority of HIV-1 infections worldwide and has been further subdivided into subtypes and sub subtypes termed A-D, F.H, J, K, and Circulating Recombinants Forms; CRF 01 to 34 $(13,14)$. Whereas several HIV-1 subtypes co-circulate in many parts of the world, some regions seem to have predominant subtypes. Subtype B is the most predominant form in North America and Europe while subtype E is highly prevalent in part of South East Asia (where B is the minority form) (15). Subtypes A, C, and D are the most common subtypes in Africa. In Mali $80 \%$ of the HIV-1 infected sex workers were subtype A, $10 \%$ belong to subtype $G$ and the minority belong to subtypes C and D (16), while in Kenya $56 \%$ of the infected subjects had subtypes A while others have subtypes C and D with other recombinants circulating forms (17).

In Nigeria, the first HIV-1 strain that was partially characterized was found to be subtype A (18). In recent time, we have co-circulation of multiple subtypes including, A, B, C, D, E and other groups in Nigeria with subtype $C$ being the most prevalent (19).

The city of Ibadan, which is acclaimed to be the largest city in West Africa, and capital of Oyo State, is a major commercial centre with long distant transport workers, migrant labour workers, civil servants and students of higher institutions which have sex with multiple female sex workers with risk of acquiring HIV infection.

The occurrences of these multiple variants of HIV in different geographical regions raise the possibility that future vaccine strategies may have to consider polyvalent constructs. The effective evaluation of vaccine candidates will depend on thorough surveillance and characterization of viral variants (20).

Since HIV infection most often results from heterosexual intercourse, female sex workers in various brothels in Ibadan are likely to be the source of detection of new subtypes that might have been introduced into the country and likely point for rapid spread of these different subtypes. Therefore this study was aimed at providing information on the sero-prevalence of HIV among female sex workers in Ibadan and also to identify the predominant subtypes of HIV-1 among them.

\section{MATERIALS AND METHODS}

\section{Study population and Sample collection}

A cross- sectional seroprevalence study was conducted in a population at high risk for HIV infection from November 2002 and July 2003 in Ibadan, South Western Nigeria. Only those subjects who were willing to participate were provided written informed consent, enrolled, and sampled. A total of two hundred and fifty Female sex workers from various brothels in Ibadan that had been in the profession for at least one month and duly signed informed consent were recruited into the study. The study protocol was approved by the University of Ibadan/ University College Hospital (UCH) ethical review committee. Semi-structured questionnaire was administered to each of the FSW who gave informed consent, as an instrument to elicit base line information on their demographic characteristics and reproductive health history.

Ten millimeters of EDTA - anti coagulated blood samples were collected from the recruited female sex workers. These samples were transported on an ice parks in an insulated box to the Diagnostic Laboratory, Virology Department, University College Hospital, Ibadan for processing. Plasma or sera were subsequently separated and stored in aliquots and maintained at $-70^{\circ} \mathrm{C}$ until tested. Clinical examinations of the lower genito-urinary tracts were carried out for signs of infections such as vaginal discharge, endocervical discharge, genital ulcer diseases and genital mass (genital warts and bartholin's cyst).

\section{Antibody Screening and Confirmation}

All the sera or plasma separated from the samples collected were screened using Enzyme Linked Immunosorbent Assay (ELISA) techniques with commercial available kits (GENSCREEN PLUS HIV by Bio-Rad in France). All reactive samples were confirmed by Western blot assay (New LAV BLOT 1 by Bio-Rad, in France).

\section{DNA Extraction and Polymerase Chain Reactions}

Qiagen kit was used for the extraction of DNA from the Peripheral Blood Mononuclear Cells separated from the whole blood of the FSWs that had been previously stored and maintained at $-70^{\circ} \mathrm{C}$. The Qiagen genomic DNA purification procedure is designed to isolate chromosomal DNA 20-150kb directly from the whole blood, buffy coat and cultured cells. Genomic DNA is eluted in a high salt buffer, concentrated and desalted by isopropanol 
precipitation. About $5 \mathrm{ul}$ of the genomic DNA of the confirmed ELISA reactive blood samples were combined with primers: WTI (KK30) and WT2 (KK40), buffers, nucleotides, taq polymerase and distilled water in a micro centrifuge tubes. Positive and negative controls were included in each run. The total volume in each tube was made up to $50 \mathrm{ul}$ in the $1^{\text {st }}$ round of PCR. Each tube was placed in a thermal cycler and subjected to PCR under the following cyclic conditions: $94^{\circ} \mathrm{C}, 55^{\circ} \mathrm{C}$ and $72^{\circ} \mathrm{C}$ for 1 minute $(5$ cycles) : $94{ }^{\circ} \mathrm{C}$ for $50 \mathrm{~s}, 57{ }^{\circ} \mathrm{C}$ for $50 \mathrm{~s}$ and $72^{\circ} \mathrm{C}$ for $1 \mathrm{mim}$ $30 \mathrm{~s}$ ( 30 cycles) and $72^{\circ}$ for 1 mimute (1Cycle)

The $2^{\text {nd }}$ round amplification was performed with 5ul of the $1^{\text {st }}$ round PCR products, primers (KK30, KK40), buffers, nucleotides, taq polymerase and distilled water adding up to $100 \mathrm{ul}$ of total volume. These were also subjected to the same cyclic conditions except that the five cycles initially were reduced to three. Detection of Amplified Products and Sequencing Detection methods that rely on size separation and visualization of PCR products include agarose and polyacrylamide gel electrophoresis $(21,22)$.

These methods allow the assessment of the presence and the size of the amplified products. Agarose gel used to separate a wide range of DNA fragment sizes. Visualization was achieved by staining the gel with ethidium bromide, a chromogen dye that binds to nucleic acid and florescence under UV light.

Genome fragments could be amplified and directly sequenced (without cloning) using a cycle-sequencing protocol adapted for the ABI automatic sequencer.

In order to determine the subtype of genome fragments or entire HIV - 1 genome, the sequences in questions were aligned with reference sequences of different known subtypes. 34 of the PCR amplified DNA fragments of the reactive ELISA and western blot confirmed HIV-1 samples were run at the APIN Laboratory, Harvard University, Department of Immunology and Infectious Diseases, Boston, U.S.A. for the identification of different subtypes by direct sequencing. Phylogenetic analysis was performed by first aligning the sequences obtained with reference sequences.

\section{Data Analysis}

Data was analyzed using SPSS for widows' version 12.0. Association between groups was performed using the chi-square test for categorical variables and student-t test for continuous variables. Logistic regression was used to adjust for potential cofounders. Analysis of variance was calculated and statistical tests were carried out at $5 \%$ significance level

\section{RESULTS}

A total of 250 Female sex workers (FSWs) from various brothels in Ibadan were enrolled and screened for HIV antibody seropositivity and predominant HIV-1/2 subtypes was determined during the period of study. As shown in Table 1, demographic characteristics of the FSWs showed that their mean age was 28.8years (Range 15-55yrs; SD = 7.35). Majority $(62.8 \%)$ were in the $20-29$ yrs age group. 174(69.6\%) were singles $37(14.8 \%)$ were divorced, $7(2.8 \%)$ were separated while $30(12.0 \%)$ were still married.

More than two-third of the uninfected FSWs (71.5\%) were single while $11.8 \%$ were married, others were divorced, separated or widowed. Majority (98.4\%) were from different parts of Nigeria while $1.6 \%$ were from Republic of Benin, Togo, Ghana and Cote d'Ivoire. Forty- one (64.1\%) of the HIV - infected FSWs had their first sexual debut between the ages of $16-20$ yrs and more than half $(57.8 \%)$ usually attended to one to five sexual partners per day. (Table1).

Sixty-four (25.6\%) of the 250 FSWs screened for antibody to HIV were confirmed HIV-1 seropositive by the Western Blot technique. Seven (2.8\%) had dual infections to HIV-1/2.There was no FSW with only HIV-2 infection. The number of HIV-1 infection was significantly higher than HIV-2 $(\mathrm{p}<0.05)$. Thus the seroprevalence of HIV-1 antibody among the Female sex workers in Ibadan was $25.6 \%$.

Among the 34 HIV-1 strains that were characterized by sequencing, 19 (55.9\%) were subtype G, 9 (26.5\%) belonged to CRF_02A/G, $3(8.8 \%)$ belonged to CRF_06cpx while $1(2.9 \%)$ each were identified as subtype C, CRF_01A/E and CRF_09cpx respectively (Table 2).

Among the 19 subtype G, 9 (47.4\%) were obtained from FSWs who hailed from Edo and Delta states in the South-south zone of Nigeria while 3 (15.3\%) were from Benue state in the middle belt zone. The only subtypes C identified was from FSW who hailed from Togo. (Table 3). The youngest (15years) of the HIV infected FSWs characterized as subtype G has been involved in sex trade for less than one year while $11(57.9 \%)$ of them have been active in the business between one to five years. Also out of the 9 characterized as CRF_02A/G, $5(55.6 \%)$ have been active in the trade between 1-5 years. This suggests that there is probability that these infections occurred very recently $(\mathrm{P}<0.05)$. 
Clinical presentations that have been found to be significantly associated with HIV-1 subtype G and CRF_02A/G were weight loss , episodes of recurrent diarrheas, skin lesions recurrent vaginal discharge and puritus vulvae $(p<0.05)$. The only clinical manifestation noticed with FSW with subtype C who hailed from Togo was recurrent genital herpes.

TABLE 1: DEMOGRAPHIC CHARACTERISTICS \& REPRODUCTIVE HEALTH HISTORY OF THE COMMERCIAL FEMALE SEX WORKERS

\begin{tabular}{|c|c|c|c|c|}
\hline CHARACTERISTICS & $\begin{array}{l}\text { FREQUENCY } \\
\mathrm{N}=250\end{array}$ & $\begin{array}{l}\text { PERCENTAGE } \\
\%\end{array}$ & $\begin{array}{l}\text { HIV POSITIVE } \\
\mathrm{N}=64\end{array}$ & $\begin{array}{l}\text { PERCENTAGE } \\
\%\end{array}$ \\
\hline 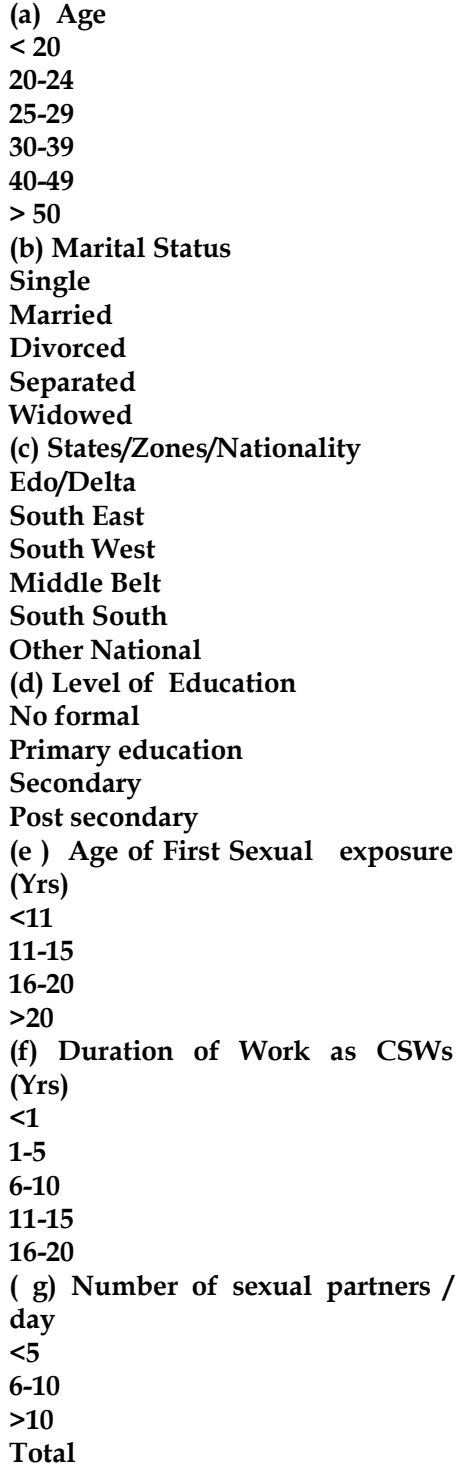 & $\begin{array}{l}32 \\
101 \\
56 \\
4 \\
13 \\
3\end{array}$ & $\begin{array}{l}12.8 \\
40.4 \\
22.4 \\
18.0 \\
5.2 \\
1.2 \\
\\
69.6 \\
12.0 \\
14.8 \\
2.8 \\
0.8 \\
\\
59.2 \\
16.4 \\
12.8 \\
6.4 \\
3.2 \\
1.6 \\
6.0 \\
34.8 \\
56.8 \\
2.4\end{array}$ & $\begin{array}{l}4 \\
28 \\
17 \\
12 \\
2 \\
1 \\
41 \\
8 \\
13 \\
2 \\
0 \\
32 \\
13 \\
5 \\
8 \\
3 \\
3 \\
3 \\
22 \\
36 \\
3 \\
\\
1 \\
17 \\
41 \\
5 \\
2 \\
37 \\
19 \\
5 \\
1 \\
64 \\
\end{array}$ & $\begin{array}{l}6.2 \\
43.8 \\
26.5 \\
18.8 \\
3.1 \\
1.6 \\
\\
64.1 \\
12.5 \\
20.3 \\
3.1 \\
0.0 \\
\\
50.0 \\
20.3 \\
7.8 \\
4.7 \\
4.7 \\
4.7 \\
34.4 \\
56.2 \\
4.7 \\
\\
1.6 \\
26.5 \\
64.1 \\
7.8 \\
3.1 \\
57.8 \\
29.7 \\
7.8 \\
1.6 \\
64.1 \\
34.4 \\
1.5 \\
100.0\end{array}$ \\
\hline
\end{tabular}


TABLE 2: DISTRIBUTION OF HIV-1 SUBTYPES AMONG FSWS

\begin{tabular}{|l|l|l|}
\hline Subtypes & Frequency & $\begin{array}{l}\text { Percentage } \\
\%\end{array}$ \\
\hline C & 1 & 2.9 \\
\hline G & 19 & 55.9 \\
\hline CRF_01 & 1 & 2.9 \\
\hline CRF_02 & 9 & 26.5 \\
\hline CRF_06 & 3 & 8.8 \\
\hline CRF_09 & 4 & 8.8 \\
\hline CRF_09 & 1 & 2.8 \\
\hline Total & 34 & 100 \\
\hline
\end{tabular}

TABLE 3: DISTRIBUTION OF HIV -1 SUBTYPES BY AGE AND NIGERIAN ZONES OF ORIGIN

\begin{tabular}{|c|c|c|c|c|c|c|}
\hline & $\mathrm{C}$ & G & CRF01 & CRF02 & CRF06 & CRF09 \\
\hline \multirow{2}{*}{$\begin{array}{r}<20 \\
20-29\end{array}$} & & $2(10.6 \%)$ & & 1(11.1\%) & & \\
\hline & $1(100 \%)$ & $14(73.5 \%)$ & $1(100 \%)$ & $4(44.4 \%)$ & $3(100 \%)$ & \\
\hline \multirow{2}{*}{$\begin{array}{l}30-39 \\
40-49\end{array}$} & & $1(5.3 \%)$ & & $3(33.3 \%)$ & & $1(100 \%)$ \\
\hline & & $1(5.3 \%)$ & & $1(11.1 \%)$ & & \\
\hline $50-59$ & & $1(5.3 \%)$ & & & & \\
\hline Zones of Origin & $\mathrm{C}$ & & CRF01 & CRF02 & CRF06 & CRF09 \\
\hline South East & & $5(26.3 \%)$ & $1(100 \%)$ & & & \\
\hline South West & & $1(5.3 \%)$ & & & & $1(100 \%)$ \\
\hline Middle Belt & & $3(15.7 \%)$ & & $9(100.0 \%)$ & $3(100 \%)$ & \\
\hline South South & & $10(53.0 \%)$ & & & & \\
\hline $\begin{array}{l}\text { Other Nationality } \\
- \\
\text { Togo }\end{array}$ & $1(100 \%)$ & & & & & \\
\hline
\end{tabular}

\section{DISCUSSION}

In Africa the highest sexually transmitted infections (STIs) and HIV infection has been reported among Female sex workers (FSWs) who are at increasing risk of acquiring and transmitting STIs and Human Immunodeficiency Virus (HIV) (17). The AIDS epidemic has exacted a terrible toll in term of life and decreased quality of life worldwide (1).

Women, especially young ones, generally lack the social power to set the terms for sexual relationship. These women live in poverty and are often coerced to trade sex for support and may be forced into prostitution. A large member of unmarried, unemployed female brothel- based sex workers are all over Ibadan and they cater for the sexual needs of the male populations, mostly of the low income group asking for payment in cash in exchange for a short sexual relationship (8).
This study showed that most of the sex workers $(75.6 \%)$ were below 30 years of age with $62.8 \%$ in the 20-29 years age group while $1.2 \%$ were over 50years of age. This is consistent with the finding of Bakare et al(9) that reported $63.3 \%$ in 20-29years age group while Umar and other researchers (23-24) reported that younger women in the age group of 20-29 years were the ones mostly engaged in sex work. This is not a surprise as there is usually higher demand for younger women by men who patronize sex workers.

The prevalence rate of HIV- 1 was $25.6 \%$. There was no sex worker with only HIV-2 infection while $2.8 \%$ had dual infections of HIV-1 and HIV-2. This prevalence was however lower than $76.0 \%$ reported in studies carried out by Egar et al in Jos (25) and $34.5 \%$ by Bakare et $\mathrm{al}(9,26)$ in Ibadan. This finding might not be unconnected with the fact that FSWs in their mid- to late thirties of age have died of undisclosed illness suspected to be AIDS. Majority of 
the younger women who are now being introduced were having protected sexual intercourse with condoms.

Human Immunodeficiency virus type-2 (HIV-2) is less pathogenic than HIV-1. Lower HIV prevalence

The genomic diversity of HIV-1 has been a continuous challenge for the development of diagnostic test, anti retroviral therapies and the development of a preventive medicine.

Among 34 HIV-1 strains characterized, more than half $(55.9 \%)$ were subtype G, $1(2.9 \%)$ belonged to subtype C. CRF02 which is the most predominant recombinant form constitutes about $26.5 \%$ of the HIV strains of the infected FSWs. 3(8.8\%) were identified as CRF_06 while others CRF_01 and CRF_09 constitutes $2.9 \%$ each respectively. This finding is similar to earlier studies of Abimiku et al (28) that reported the presence of subtype $\mathrm{G}$ from Jos, Nigeria. It is however different with other studies where subtype G infections have been described in diverse locations from East to West Africa, though rarely as a major proportion of the infection (29)

In different locations in Africa like Mali, Republic of Benin, Nigeria and Democratic Republic of Congo, subtype G rarely account for more than $20 \%$ all HIV-1 infections. This is the first time that the prevalence of HIV-1 subtype G is exceeding $50 \%$ of the HIV strains identified. Contrary to the study conducted in Nigeria by Odaibo et al (30), a heterogeneous distribution of at least 5 subtypes were observed with subtype $C$ being the most predominant in the south-western part of Nigeria.

In a similar study conducted in Bamako, Mali among the female sex workers (FCSWs) (16), it was reported that subtype A was the predominant HIV strain identified among them while $15.1 \%$ were subtype G . Subtype A was not detected in this study.

HIV subtype B that is the most prevalent in Western Europe and North America has not been linked with any major epidemics in Africa (31-32). Though the prevalence was $2.5 \%$ in the study conducted by Odaibo in 1999(30), it was not detected in this study. The prevalence of subtype $C$ in this study was low $(2.9 \%)$ and the only infected FSW with this subtype migrated from Togo to Nigeria. This is however contrary to other reports which indicated that subtype $\mathrm{C}$ was the most prevalent subtype in HIV-1 pandemic and it has been found to account for the majority of the intense epidemic observed in South Africa and Ethiopia (33-34). Subtypes D \& F were not detected in this study but they had been found to be the most prevalent subtype in Uganda and Kenya (3536). recorded in this study was consistent with other studies reported in selected populations in other African countries $(23,24)$.

Among HIV-1 circulating recombinants forms, CRF02 was the predominant and accounted for $26.5 \%$ of the HIV-1 strains identified in this study. This CRF often designated as " $1 \mathrm{bNG}$ ", the name given to the first sample described from Ibadan, Nigeria (37). This is contrary to the earlier study(30) where $18.9 \%$ of the strains belonged to subtype A. Many of the genomes within the 1bNG CRF cluster may have been erroneously classified as subtype A. This subtype has been responsible for regional epidemics along the coast of West and East Africa (38).

Detection of the CRF 06 cpx-a complex recombinants between Subtypes A, G, J, and K which constituted $8.8 \%$ in this study was in agreement with the findings of Montavon et al (39). However, this was the first time this complex recombinant form has been isolated in Nigeria.

CRF01-AE which has been responsible for a large number of infections in Thailand(40) and other Southeast Asian countries (40) was detected in this study, though the prevalence was low $(2.9 \%)$.

Information about recombinant CRF_09 cpx is very limited (13). Its detection in this study would however form a baseline data for further studies in this part of the country. The youngest of the HIV infected FSWs with sexual activity of less than a year had HIV-1 Subtype G while $55.9 \%$ of the FSWs with subtype $G$ have been active in the commercial sex work between 1-5years. These findings gave a significant probability that infections with this subtype occurred very recently and it has very short incubation period $(\mathrm{P}<\mathrm{O} .05)$. The report was also similar with that of Peeters et al (16), which stated that among the 10 HIV-1 subtype G strains obtained, 8 were from younger FSWs with an activity of less than a year.

All the HIV-1 infected FSWs who had subtypes G, CRF01, CRF02, CRF06 and CRF09 usually engaged in heterosexual mode of intercourse while FSW with subtype C usually practiced bisexual mode of intercourse. There is significant statistical relationship between bisexual mode of intercourse and HIV infection.

\section{CONCLUSION}

Until the problem of economic development in Nigeria is tackled, convincing young people to adapt their sexual behaviours to secure their future remains difficult. The recent renewed international attention on HIV/AIDS epidemics in sub-Saharan African should translate to commitment to reconstruct social services and to tackle economical underdevelopment. 
Additional efforts are needed to provide alternative economic choices for young women.It is important to continue the surveillance of subtypes on a systematic basis in order to see to what extent the proportions of the different subtypes will change over time. Since there are diverse circulating strains of HIV in the country, a polyvalent vaccine will be required for effective preventive prophylaxis against HIV in Nigeria. Given this diverse nature of HIV-1 subtypes, this epidemic may well be more challenging for HIV vaccine candidate design than previously anticipated.

\section{REFERENCES}

1. World Health Organization (WHO). AIDS epidemic update: December 2002 (WHO, Geneva, 2002).

2. World Health Organization (WHO), Global AIDS surveillance, weekly Epidemiology, 1998, 73; June (26), 193-200.

3. Odaibo, G.N, Olaleye O. D. and Tomori, O, Human Immuno deficiency virus type 1 and 2 infection in some rural area in Nigeria. $1^{\text {st }}$ international urology and microbiology conference Nov 1996. Yaoundé. Cameroon.

4. Esu-Williams E, Malanga-Kabeya C., Takena H. et al. Seroprevalence of HIV-1, HIV-2 and HIV-1 group $\mathrm{O}$ in Nigeria: evidence for a growing increase of HIV infection. Journal of Acquired Immune Deficiency syndromes. 1997. 16(3): 204-210.

5. Umar, U.S., Bakare, R. A. and Umar, A.S. HIV/AIDS in Rural Nigeria: Opportunities for integrating care and support for PLWHA into the Community. In: XIV International AIDS conference 2002. Barcelona, July 712.Monduzzi Editore S.p.A.; 391-398.

6. Paris, P., HIV and India: Looking into the abyss. Tropical Medicine and International health ; 1996; 295-304.

7. 2006 Report on the global AIDS epidemic, UNAIDS, May 2006 [http://www.unaids.org/en/Publications/ default.asp] website

8. Ekvenzor, C.E, Olaleye, O.D., Tomori, O, Saliu I, Essien E.M., Bakare, R. A. ,Oni, A.A., Oyewo, O. O., et al. Clinico-Epidemiological patterns of HIV infection in STD patients in Ibadan. African Journal of Medicine ; 1995; 24: 321-327.

9. Bakare R.A., Oni, A.A., Umar U.S. Shokunbi W. A., Fayemiwo, S. A., Fasina N. A. Pattern of sexually transmitted diseases among commercial sex workers in Ibadan ,Nigeria. African Journal of Medicine; 2001; 31: $243-$ 246.

10. Nowo G., Forde, A. Macronnel P. and Fahrenwald R., In -situ detection of PCR -

\section{ACKNOWLEDGEMENTS}

The Authors would like to appreciate all resident doctors, public health nurses and laboratory staff of Special Treatment Clinic and Virology Department, University College Hospital, Ibadan for assistance and encouragement during the study. The AIDS Prevention Initiatives in Nigeria (APIN), Harvard School of Public Health, USA, study participants and directors of the selected brothels are also thankfully acknowledged.

amplified HIV-1 nucleic acids and tumour necrosis factor cDNA in cervical

tissue. American Journal of Pathology .1993;143: 2860-2864.

11. Bagasra. O., Farzadehgar H, Seshamma T et al. Detection of HIV-1 proviral

DNA in sperm from HIV-1 infected men. AIDS. 1994;8: 1669-74.

12. Omu, A.A. Nico J.D, Nagel kerke et al, Rapid progression to disease in African sex workers with HIV-1. The Journal of infectious Diseases, 1995; 171: 686-9.

13. McCutcham, F. E., Understanding genetic diversity of HIV-1. AIDS, 2000: 14 (supplement) S31-S44.

14. Maria A Pando, Lindsay M Eyzaguirre , Gladys Carrion, Silvia M Montano, José L Sanchez, Jean K Carr and María M Avila . High genetic variability of HIV-1 in female sex workers from Argentina. Retro virology 2007, 4:58 doi: 10.1186/1742-4690-4-58

15. McCutchan F.E., Hegerich, P.A, Brannam, T.P et al. Genetic Variants of HIV -1 in Thailand. AIDS Research and Human Retroviruses; 1992: 1837-95.

16. Peters, M. Koumare, B. Mulanga, C., et al. Genetic Subtype of HIV-1 and HIV-2 strains in commercial sex workers from Bamako, Mali. AIDS Research and Human Retroviruses. 1998; 14(1): 51-58.

17. Khoja S, Ojwang $\mathrm{P}$, Khan S, Okinda N, Harania R, et al. Genetic Analysis of HIV-1 Subtypes in Nairobi, Kenya. PLoS ONE 2008: 3(9): e3191. doi:10.1371/journal.pone.0003191

18. Olaleye, O. D., Sheng, Z. Howard, J. and Rasheed S. S., Isolation and biological characterization of a new HIV-1 strains in Nigeria. Journal of virology (In press).

19. Odaibo, G. N. Olaleye, O. D. Ruppach, H., Okafor, O. G. and Dietrich U., Multiple Presence and Heterogeneous distribution of HIV-1 subtypes in Nigeria. Biosciences Research Communication;13(4): 447-458. 
20. Hu. D.G., Dondero, T. J., Rayfield, et al. The emerging genetics diversity of HIV: The importance of Global surveillance for diagnostic Research and prevention. .Journal of American Medical Association. 1996; 275(3):210-216.

21. Umar U.S. Knowledge, Attitude, Preventives practices and treatment seeking behaviour regarding sexually transmitted diseases among Commercial Sex Workers (CSWs) in Ibadan. A dissertation submitted for the degree of Masters of Public Health, University of Ibadan. October, 1998.

22. Onile, B.A. and Odugbemi Tolu,. Genital Ulcer Diseases in Ilorin. African Journal of clinical and Experimental Microbiology. 2002; 3(1):21-23.

23. Bufe, A. Bishikwabo-Nsarhaza, K. Mutangadura G. The spread and effect of HIV-1 Infection in sub- Saharan African; Lancet. 2002; 359:2011-17.

24. Zalu ,E., Ezeh ,A.C., NiiAmooDoddo, F., Slum residence and sexual outcomes : early findings of casual linkages in Nairobi, Kenya (working paper No 17):African population and Research center.

25. Egah, D.Z., Imade, G.E. Sagay A.S., et al.HIV-1 infections among patients with genital ulcer diseases in Jos .Nigeria. African Journal of clinical and Experimental Microbiology. 2002;3: 272-77.

26. Bakare R.A., Oni,A.A., Umar,U.S., Kehinde,A,O., Fayemiwo,S.A. ,Fasina,N.A .Adewole,L.F. and Shokunbi,W.A. Prevalence of Trichomonas vaginalis amongst commercial Sex Workers (CSWs) In Ibadan , Nigeria. African Journal Of Clinical and Experimental Microbiology.2002;3/2:72-77.

27. Mulanga-kabeya,C., Nzilambi,N, Edidi, B. et al. Evidence of stable HIV seropositive in selected populations in the Democratic Republic of Congo. AIDS.

1998;12(8):905-910.

28. Abimiku, A.G., Stern T.L., Zirandov A. et al. Subtype G HIV-1 Isolate in Nigeria AIDS Research \& Human Retroviuses .1994;10: 1581-1583.

29. Vidal N., Petewrs, M., Mulanga -Kabeya C., et al. Unprecedented degree of human immunodeficiency virus (HIV)group M genetic diversity in Democratic Republic of Congo suggest HIV pandemic originated in central Africa. Journal of Virology.2001; 74:10498-10507.

30. Odaibo, G.N. HIV-1 serotypes and some aspects of phenotypic properties of the virus isolates in Nigeria. Ph.D Thesis. University of Ibadan ,Nigeria. July, 1999.

31. Tkehisa,J., Zekeng, L., Muira, T. et al Various types of HIV-1 mixed infections in Cameroon . 1998; 245; 1-10.

32. Nkengasong, J.N., Janssens, W., Heyndrick, X.L .et al. Genetic Subtypes of HIV-1 in Cameroon. AIDS.1994; 8:1405-1412.

33. Heyndrick, X.L.,Janssens, W. Zekeng, L.,et al. Simplified strategies for the detection of recombinants human immunodeficiency virus type 1 group $\mathrm{M}$ isolates by gag / env Heteroduplex Mobility Assay: Study group on heterogeneity of HIV epidemics in African cities. Journal of Virology. 2000; 74:63-370.

34. Abebe ,A., Lukashov V.V.,Polakis G., et al. Timing of HIV -1 subtype $C$ epidemics in Ethiopia based on early virus strains and subsequent virus identification. AIDS.2001; 1555-1561.

35. Janssens, W., Heyndrick, L., Fransemk, et al. Genetic variability of HIV type I in Kenya. AIDS Resource \& Human Retroviruses, 1994; 10: 1577-1579.

36. Buonagaro, L, Del Guadio, E. Mon alo M, etal. Heteroduplex Mobility Assay and Phylogenetic analysis of viz region sequences of HIV - 1 no9lates from Guldw. Northern Uganda. The Italian - Uganda Cooperation AIDS Programme. Journal of Virology, 1995, 69; 7971-79

37. Howard, T. M., Olaleye D.O., Rasheed S.I Sequence analysis of the glycoprotein 120 cooling region of a new HIV type 1 substype A strain (HIV - $1 \mathrm{Ib} \mathrm{Ng}$ ) from Nigeria. AIDS Human Retroviruses 1994; 10: 1755-57.

38. Toure-kane C., Montavon C., Faye, M. A. et al . Identification of all HIV type group $\mathrm{M}$ subtypes in Senegal, a country with low and stable seroprevalence. AIDS Research and Human Retroviruses 2000, 16 ; 603-609.

39. Montavon C, Bibollet-Ruche F, Robertson D. et al. The identification of a complete - 01 A/G/I/J recombinant HIV type 1 in various West Africa Countries. AIDS. Resource \& Human Retroviruses, 1999; 15:1707 1712.

40. Weginer B. Experience from Incidence cohorts in Thailand: Implication for HIV Vaccine efficacy trials. AIDS; 1994, 8: 1007 1010.

41. Beyer C. Rasak M. H., Lisum K, et al, Overland Heroin trafficking routes and HIV - 1 spread in South and South -East Asia. AIDS, 2000.14: 75-83. 